\title{
Isolation, culture and biological characteristics of multipotent porcine tendon-derived stem cells
}

\author{
JINJUAN YANG $^{1,2^{*}}$, QIANJUN ZHAO ${ }^{1 *}$, KUNFU WANG $^{1}$, CAIYUN MA $^{1}$, \\ HAO LIU ${ }^{1}$, YINGJIE LIU ${ }^{2}$ and WEIJUN GUAN ${ }^{1}$ \\ ${ }^{1}$ Department of Animal Genetic Resources (AnGR), Institute of Animal Science, \\ Chinese Academy of Agricultural Sciences, Beijing 100193; ${ }^{2}$ Institute of Physical Education, \\ University of Jimei, Xiamen, Fujian 361021, P.R. China
}

Received September 12, 2016; Accepted January 24, 2018

DOI: $10.3892 / \mathrm{ijmm} .2018 .3545$

\begin{abstract}
Tendon-derived stem cells (TDSCs), a postulated multi-potential stem cell population, play significant role in the postnatal replenishment of tendon injuries. However, the majority of experimental materials were obtained from horse, rat, human and rabbit, but rarely from pig. In this research, 1-day-old pig was chosen as experimental sample source to isolate and culture TDSCs in vitro. Specific markers of TDSCs were then characterized by immunofluorescence and reverse transcription polymerase chain reaction (RT-PCR) assays. The results showed that TDSCs could be expanded for 11 passages in vitro. The expression of specific markers, such as collagen I, collagen III, $\alpha$-smooth muscle actin ( $\alpha$-SMA), CD105 and CD90 were observed by immunofluorescence and RT-PCR. TDSCs were induced to differentiate into adipocytes, osteoblasts and chondrocytes, respectively. These results suggest that TDSCs isolated from porcine tendon exhibit the characteristics of multipotent stem cells. TDSCs, therefore, may be potential candidates for cellular transplantation therapy and tissue engineering in tendon injuries.
\end{abstract}

\section{Introduction}

Tendon, a compositional complex connective tissue, translates muscular contractions into joint movement by transmitting

Correspondence to: Professor Yingjie Liu, Institute of Physical Education, University of Jimei, No. 185 Yinjiang Road, Jimei District, Xiamen, Fujian 361021, P.R. China

E-mail: yangxiaonuodexiao@163.com

Dr Weijun Guan, Department of Animal Genetic Resources (AnGR), Institute of Animal Science, Chinese Academy of Agricultural Sciences, No. 2 Yuanmingyuan West Road, Haidian District, Beijing 100193, P.R. China

E-mail: weijunguan301@gmail.com

${ }^{*}$ Contributed equally

Key words: porcine, tendon-derived stem cells, identification, multi-differentiation potential, biological characteristics forces from muscle to bone. Bone-tendon injuries, tendon rupture and ligament injuries are very common in daily life and in sports $(1,2)$ which commonly occurs following rapid change of direction, deceleration, landings, overuse or degeneration. These injuries heal slowly and often result in the formation of mechanically and functionally inferior fibrotic scar tissue (3). Several biological factors, such as, local intraligamentous cytokines and cell repair mechanism controlled by stem cells (4), affect the healing process of injured tendons. Due to the few efficient treatments and the high recurrence rates of the repair of tendon injuries, the development of novel treatments with higher reliability and efficacy is the foremost issue to improve outcomes for athletes and patients suffering tendon injuries.

Stem cells, due to their strong self-renewal ability and tissue regeneration capacity, have been studied for the treatment of tissue defect and dysfunction in vitro $(5,6)$. Tendon stem cells have been identified recently and considered an optimal cell source for tendon repair. The isolation and identification of pig tendon-derived stem cells (TDSCs) are necessary as pig is one of most important economic animals and make a significant contribution towards meeting human nutritional requirements; pig TDSCs will also provide a new tool to study the physiological mechanism of tendinopathy and the basic tendon biology. Current research of TDSCs focuses on tendon tissues of varies species, including humans, mice, rabbits, and other mammals, but little research has been performed on the pig $(5,7,8)$. The goal of our study was to detect whether pig tendon tissues harbor cells with stem-cell characteristics. We carried out a pilot study on the isolation, culture, differentiation potential and biological characteristics of TDSCs of pig. Finally, further directions for promoting tendon repair are discussed.

\section{Materials and methods}

Isolation and culture of porcine TDSCs. The animal experiments were performed in accordance with the guidelines established by the Institutional Animal Care and Use Committee of the Chinese Academy of Agriculture of Sciences. The Bama miniature pig (1-day-old) was obtained from the farm of the Chinese Academy of Agriculture of Sciences. The experimental protocols were approved by the 
Institutional Animal Care and Use Committee of the Chinese Academy of Agriculture of Sciences [permit no. SCXK (jing) 2015-0006].

Tendon tissues were dissected from Achilles tendon of 1-day-old pig, the process of experiments followed those described previously $(9,10)$, the mid-substance tendon tissue was excised from healthy pig, peritendinous connective tissue was removed, and the sample was washed in sterile phosphate-buffered saline (PBS). The tissue was cut into approximately $1 \mathrm{~mm}^{3}$ pieces using ophthalmic scissors. Then digested with-type I collagenase ( $3 \mathrm{mg} / \mathrm{ml}$; Sigma-Aldrich, St. Louis, MO, USA) for $1.5 \mathrm{~h}$ at $37^{\circ} \mathrm{C}$. The enzymatic activity was neutralized with fetal bovine serum (FBS) (Gibco, Carslbad, CA, USA) and passed through a $70 \mu \mathrm{m}$ cell strainer (Becton, Dickinson and Co., Franklin Lakes, NJ, USA) to yield single-cell suspension and then centrifuged at 1,200 rpm for $8 \mathrm{~min}$ at room temperature, the released cells were resuspended in low-glucose Dulbecco's modified Eagle's medium (L-DMEM; Gibco), 15\% FBS (Biochrom GmbH, Berlin, Germany), 100 U/ $\mathrm{ml}$ penicillin, $100 \mathrm{mg} / \mathrm{ml}$ streptomycin, $2 \mathrm{mM}$ L-glutamine, $0.4 \mathrm{ng} / \mathrm{ml}$ epidermal growth factor (EGF), $2.5 \mathrm{ng} / \mathrm{ml}$ basic fibroblast growth factor (bFGF) and $2.5 \mathrm{ng} / \mathrm{ml}$ stem cell factor (SCF) (complete culture medium) (all from Invitrogen Life Technologies, Carlsbad, CA, USA). Cells were seeded in $60 \mathrm{~mm}$ Petri dish and cultured at $37^{\circ} \mathrm{C}$ with $5 \% \mathrm{CO}_{2}$. After $48 \mathrm{~h}$ of initial plating, the cells were washed twice with L-DMEM to remove non-adherent ones. At about day 7 or 8 , when large adherent cell confluence reached approximately $80-90 \%$, it was labelled as passage $0(\mathrm{P} 0)$, then digested with $0.125 \%$ trypsin added with $0.02 \%$ EDTA (Gibco) and subcultured at a ratio of 1:1. The medium was refreshed once each 2 days. Normally, cells after passage 3 were homogenous and purified, and could be used for the experiments.

Optimization of cell culture cystems for TDSCs. Cells at passage 2 were assessed after culturing in three different culture systems, the composition of the cell medium is shown in Table I: culture system I (L-DMEM supplemented with $2 \mathrm{mM}$ L-glutamine, $15 \%$ FBS and $1 \%$ penicillin-streptomycin mixture, $0.4 \mathrm{ng} / \mathrm{ml}$ EGF), culture system II (L-DMEM supplemented with $2 \mathrm{mM}$ L-glutamine, $15 \%$ FBS, $0.4 \mathrm{ng} / \mathrm{ml}$ EGF

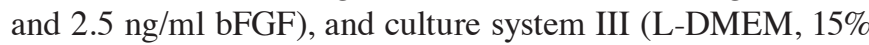
FBS, 2 mM L-glutamine, $0.4 \mathrm{ng} / \mathrm{ml}$ EGF, $2.5 \mathrm{ng} / \mathrm{ml} \mathrm{bFGF}$ and $2.5 \mathrm{ng} / \mathrm{ml} \mathrm{SCF}$ ). Cells were harvested and reseeded in 6-well plates at $5 \times 10^{4}$ cells/well. Cells cultured in three culture systems were counted in each passage 3 times. Culture system III was used for the subsequent cell expansion experiments in vitro.

Growth kinetics of pig TDSCs. To detect the proliferative capacity of pig TDSCs in vitro, cells at P3, P6 and P10 were plated to 24-well microplates at a density of $1 \times 10^{4}$ cells/well, cultured for 8 days and counting were performed in 3 wells every day, cells counting per well was repeated 3 times to calculate the mean. The population doubling time (PDT) was calculated as follows: $\mathrm{PDT}=\left(\mathrm{t}-\mathrm{t}_{0}\right) \lg 2 /\left(\lg \mathrm{N}_{\mathrm{t}}-\lg \right), \mathrm{t}_{0}$, starting time of culture; $t$, termination time of culture; $\mathrm{N}_{0}$, initial cell number of culture; $\mathrm{N}_{\mathrm{t}}$, ultimate cell number of culture $(11,12)$.

Colony-forming cell assay of TDSCs. For assays of colony-forming efficiency, cells from P2, P6, P8 and P10 were seeded in 6-well plates at a density of $1 \times 10^{3}$ cells/well. After culturing for 10 days, colonies were observed under inverted microscope. To assess colony-forming efficiency of TDSCs, the culture medium was removed, cells were washed with PBS 3 times and then fixed with $4 \%$ paraformaldehyde for $20 \mathrm{~min}$, after that cells were stained with freshly prepared Giemsa dye for $30 \mathrm{~min}$ and finally the dye was irrigated with flowing water gently. The number of colony-forming units (CFUs) was counted to calculate the colony-forming rate, which is formulated as: (CFU number/starting cell number/6-well) x100\%, the procedure was repeated 6 times for each passage.

Karyotype analysis. Karyotype of pig was analyzed according to the protocol of previous research (13). Karyotype were examined by using colchicine and Giemsa stain. Cells at different stages were collected after incubating in culture medium added with colchicine for $24 \mathrm{~h}$, during which, most cells were arrested in metaphase, subjected to hypotonic treatment and fixed, the cells were dropped on a slide glass and stained with Giemsa. Finally, the numbers of chromosome were counted for 100 metaphase spreads under an oil immersion objective upon Giemsa staining. Relative length were calculated based on previous studies (14).

\section{Identification of porcine TDSCs}

Surface marker detection of porcine TDSCs. The protocol for immunocytochemistry was described previously (15-18), porcine TDSCs were rinsed in PBS and fixed in $4 \%$ paraformaldehyde for $20 \mathrm{~min}$ and washed in PBS 3 times, then permeabilized with $0.2 \%$ Triton X-100 for 20 min and washed in PBS 3 times. TDSCs were blocked with $10 \%$ goat serum (Santa Cruz Biotechnology, USA) for $20 \mathrm{~min}$ and then incubated in $5 \%$ bovine serum albumin (BSA) at room temperature for $1 \mathrm{~h}$. Added primary antibodies: rabbit anti-collagen I antibody, rabbit anti-collagen III antibody (19), rabbit anti- $\alpha$-smooth muscle actin ( $\alpha$-SMA) antibody, rabbit anti-CD90 antibody, rabbit anti-CD105 antibody (12), (1:10; BIOSS, Beijing, China) dilution of target cell markers at $4^{\circ} \mathrm{C}$ overnight. The primary antibodies were removed and the cells were washed 3 times with PBS, FITC-goat anti-rabbit secondary antibody (1:100; Zhongshan Golden Bridge Biotechnology Co., Ltd., Beijing, China) was added and incubated at room temperature in the dark for $1 \mathrm{~h}$. The secondary antibody solution was decanted and washed 3 times with PBS in the dark. The cells were incubated in $1 \mu \mathrm{g} / \mathrm{ml}$ DAPI (Sigma-Aldrich) for $15 \mathrm{~min}$ and washed 3 times with PBS. Finally, images were taken with a laser scanning confocal microscope (Nikon, Yokohama, Japan).

Real-time PCR assay. Total RNA of TDSCs was extracted following published method $(20,21)$. Briefly, cells at passages 3 and 6 were collected and total RNA was extracted using TRIzol reagent (Invitrogen Life Technologies). RNA concentrations were reverse transcribed followed by 35 PCR cycles using RNA PCR kit ver 3.0 (Takara Bio., Inc., Dalian, China). The RT-PCR was continued for 35 cycles after an initial denaturation at $94^{\circ} \mathrm{C}$ for $2 \mathrm{~min}$. Each cycle of PCR consisted of $94^{\circ} \mathrm{C}$ for $30 \mathrm{sec}$, annealing temperature for $30 \mathrm{sec}$ and $72^{\circ} \mathrm{C}$ for $30 \mathrm{sec}$, as well as a final extension of $10 \mathrm{~min}$ at $72^{\circ} \mathrm{C}$ and the entire reaction was chilled and stored at $4^{\circ} \mathrm{C}$ until analysis. PCR products were visualized with ethidium bromide on $2 \%$ agarose gel electrophoresis. The primers used in this study 
Table I. Optimization of cell culture systems for porcine TDSCs.

\begin{tabular}{|c|c|c|c|}
\hline & $\begin{array}{c}\text { I } \\
\text { L-DMEM }\end{array}$ & $\begin{array}{c}\text { II } \\
\text { L-DMEM }\end{array}$ & $\begin{array}{c}\text { III } \\
\text { L-DMEM }\end{array}$ \\
\hline Basic content & $\begin{array}{c}15 \% \text { FBS } \\
\text { Penicillin-streptomycin } \\
2 \text { mM L-glutamine }\end{array}$ & $\begin{array}{c}15 \% \text { FBS } \\
\text { Penicillin-streptomycin } \\
2 \mathrm{mM} \text { L-glutamine }\end{array}$ & $\begin{array}{c}15 \% \text { FBS } \\
\text { Penicillin-streptomycin } \\
2 \mathrm{mM} \text { L-glutamine }\end{array}$ \\
\hline Additional content & $0.4 \mathrm{ng} / \mathrm{ml} \mathrm{EGF}$ & $\begin{array}{c}0.4 \mathrm{ng} / \mathrm{ml} \mathrm{EGF} \\
2.5 \mathrm{ng} / \mathrm{ml} \mathrm{bFGF}\end{array}$ & $\begin{array}{c}0.4 \mathrm{ng} / \mathrm{ml} \text { EGF } \\
2.5 \mathrm{ng} / \mathrm{ml} \mathrm{bFGF} \\
2.5 \mathrm{ng} / \mathrm{ml} \mathrm{SCF}\end{array}$ \\
\hline
\end{tabular}

TDSCs, tendon-derived stem cells; L-DMEM, low-glucose Dulbecco's modified Eagle's medium; FBS, fetal bovine serum; EGF, epidermal growth factor; bFGF, basic fibroblast growth factor; SCF, stem cell factor.

Table II. Primer sequences and condition for RT-PCR.

\begin{tabular}{|c|c|c|c|}
\hline Gene & Primer sequences & $\operatorname{Tm}\left({ }^{\circ} \mathrm{C}\right)$ & Product length (bp) \\
\hline \multirow[t]{2}{*}{ Collagen I } & F 5'-CGGCAATGTGTTGTGCGATGAC-3' & 62 & 269 \\
\hline & R 5'-GAGACCACGAGGACCAGAAGGA-3' & & \\
\hline \multirow[t]{2}{*}{ Collagen II } & F 5'-CCTCTGCGACGACATAATCTGTGA-3' & 62 & 424 \\
\hline & R 5'-TCTCATCGAATCCTCCAGCCATCT-3' & & \\
\hline \multirow[t]{2}{*}{ Collagen III } & F 5'-CTGCTGCCATCGCTGGTGTT-3' & 62 & 284 \\
\hline & R 5'-TGCCAACTGGACATCAAGGACATC-3' & & \\
\hline \multirow[t]{2}{*}{ GAPDH } & F $\quad$ 5'-GTGAAGGTCGGAGTGAACGGATT-3' & 62 & 275 \\
\hline & R 5'-GGAGGCATTGCTGACGATCTTG-3' & & \\
\hline \multirow[t]{2}{*}{ LPL } & F 5'-ATGGCTGGACGGTGACAGGAAT-3' & 63.8 & 513 \\
\hline & R 5'-CACGGATGGCTTCTCCAATGTTACA-3' & & \\
\hline \multirow{2}{*}{ PPARr } & F 5'-ACCАСТСССАСТССТТТGАСАТСА-3' & 63.6 & 510 \\
\hline & R 5'-TCTCTGCCAACAGCTTCTCCTTCT-3' & & \\
\hline \multirow[t]{2}{*}{ SOX9 } & F 5'-GCTCTGTGCTCTACTCCACCTTCA-3' & 64 & 413 \\
\hline & R 5'-CTGTCGGTTCTGCTGGTCCTCT-3' & & \\
\hline \multirow[t]{2}{*}{ OPN } & F 5'-GGAGGAAACGGACGACTTCAAACA-3' & 63.6 & 334 \\
\hline & R 5'-GGCTTCGGATCTGCGGAACTTC-3' & & \\
\hline \multirow[t]{2}{*}{ Runx2 } & F 5'-CTACCAGCCACCGAGACCAACA-3' & 64 & 470 \\
\hline & R 5'-GCAGCACAGAGCACAGGAAGTT-3' & & \\
\hline \multirow[t]{2}{*}{ ALP } & F 5'-TCCACGAGCAGAACTACATCC-3' & 59.3 & 304 \\
\hline & R 5'-AGGCAGACTTTGGTTTCCTG-3' & & \\
\hline \multirow[t]{2}{*}{ ACAN } & F 5'-CAGGCTCCAACGGCTCAAGAAG-3' & 64 & 557 \\
\hline & R 5'-AAGGCAGAGGTGGCTTCAGTCA-3' & & \\
\hline
\end{tabular}

were designed with Primer Premier 5.0 software, and the product sizes, annealing temperatures and primer sequences are listed in Table II.

Multipotent differentiation of TDSCs in vitro. For the detection of osteogenesis, adipogenesis and chondrogenesis, TDSCs were cultured in completed medium as control group and in induction medium as induction group for $14-28$ days at $37^{\circ} \mathrm{C}$ with $5 \% \mathrm{CO}_{2}$.

The chondrogenic induction medium consisted of basic growth medium added with $40 \mathrm{mg} / \mathrm{ml}$ prolin, $50 \mathrm{ng} / \mathrm{ml}$ dexamethasone, $10 \mathrm{ng} / \mathrm{ml}$ TGF- $\beta 3,50 \mathrm{mg} / \mathrm{ml}$ ascorbate 2-phosphate, $100 \mathrm{mg} / \mathrm{ml}$ sodium pyruvate and $50 \mathrm{mg} / \mathrm{ml}$ insulin-transferrin-selenious acid mix (ITS;
Sigma-Aldrich) (10,22). The osteogenic induction medium consisted of basic growth medium supplemented with $1 \mathrm{nM}$ dexamethasone, $50 \mu \mathrm{M}$ ascorbic acid, $10 \mathrm{mM} \beta$-glycerol phosphate (Sigma-Aldrich) $(17,23)$. The adipogenic induction medium consisted of basic growth medium supplemented with $500 \mathrm{nM}$ dexamethasone, $100 \mathrm{mM}$ indomethacin (Sigma-Aldrich), $0.5 \mathrm{mM} 3$-isobutyl-1-methyl xanthine, and $10 \mathrm{mg} / \mathrm{ml}$ insulin. After 14-21 day culture, TDSCs cultured in complete medium and in induction medium were collected for RT-PCR or fixed in $4 \%$ paraformaldehyde for $20 \mathrm{~min}$ at room temperature, washed with PBS 3 times, then stained with Alcian blue 8GX solution (Sigma-Aldrich), Alizarin Red S solution (Amresco LLC, Solon, OH, USA) and $0.3 \%$ Oil Red O solution (Sigma-Aldrich), respectively. 

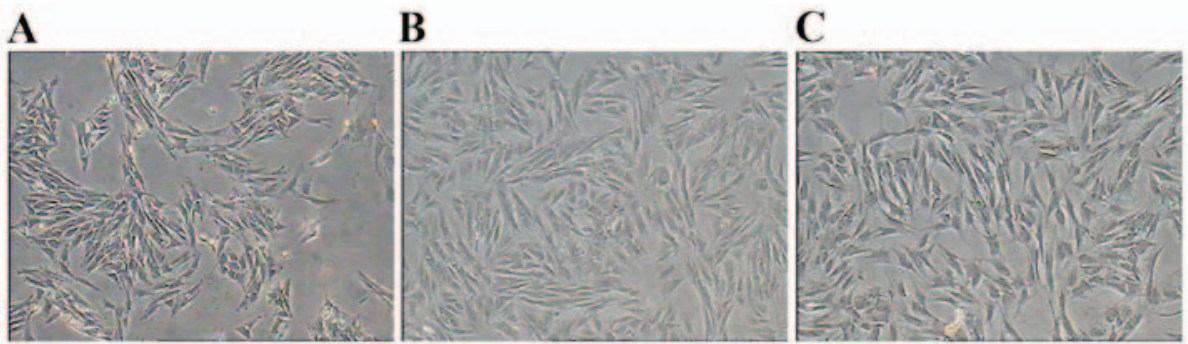

D

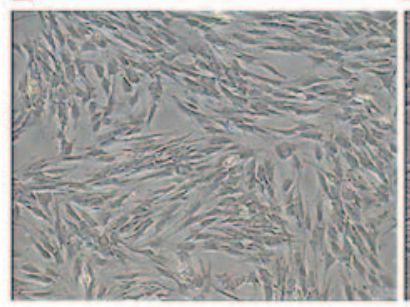

$\mathbf{E}$

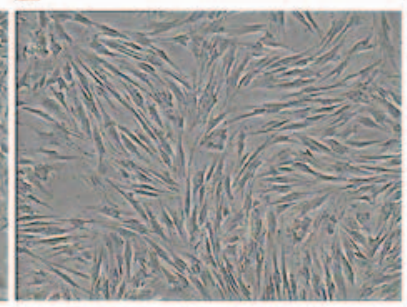

F

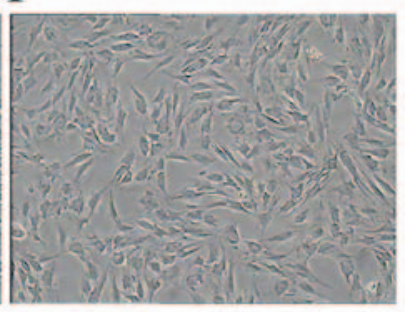

$50 \mu \mathrm{m}$

Figure 1. Morphology of primary cultured and subcultured pig TDSCs. (A) After $48 \mathrm{~h}$ of primary culture, TDSCs began to adhere to plates (magnification, $\mathrm{x} 40$ ). (B) Freshly isolated cells cultured for 5 days (magnification, $\mathrm{x} 40$ ). (C-E) Cells of passages 3, 6 and 9 showed typical fibroblast fusiform (magnification, $\mathrm{x} 40$ ). (F) Porcine TDSCs of passage 11 showed senescence (magnification, x40). Scale bar, $50 \mu \mathrm{m}$. TDSCs, tendon-derived stem cells.

Finally, samples were observed under an inverted microscope and photographed.

\section{Results}

Morphology of porcine TDSCs at different passages. Observed with an inverted microscope, primary cells isolated from tendon tissues began to adhere to culture plates after $48 \mathrm{~h}$ (Fig. 1A) and grew to $80 \%$ confluence approximately 5 days later (Fig. 1B). After passage 3, cells were purified and there were no obvious morphology differences among the different passages, showing typical fibroblast fusiform morphology (Fig. 1C-E). The highest number of passages achieved in this study was 11, after which most cells displayed senescence and finally detached from the plates (Fig. 1F).

Optimization of cell culture systems for TDSCs. Generally, the complete culture medium was selected to render higher proliferation ability, maintain cell immaturity and reduce cell differentiation in the process of their proliferation in vitro. Through a series trial, we determined the optimal proliferation medium for porcine TDSCs in vitro. As is shown in Fig. 2, there was no significant difference between culture I and II, whose generation time was about 5-7 days for both systems ( $>0.05)$, the generation time of culture system III was about $3.24 \pm 0.26$ days, which was obviously different from others $(\mathrm{P}<0.05)$. Through long-term cell culture in three media, cells cultured in culture system III possessed the best proliferation ability for long time in vitro. Consequently, culture system III is optimal for proliferation of porcine TDSCs and was chosen for experiments in this study. We hold the opinion that the combination of bFGF and EGF could promote proliferation of porcine TDSCs in vitro.

Growth kinetics of porcine TDSCs. The growth curves of TDSCs from three different passages, which were all typically sigmoidal, are shown in Fig. 3. Porcine TDSCs were similar at

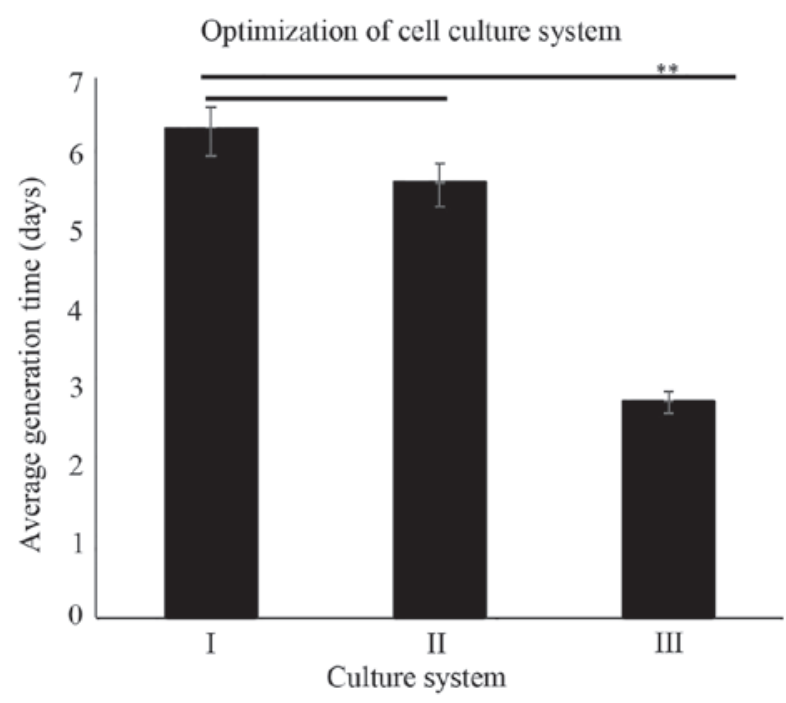

Figure 2. Comparison of average generation time in the different culture systems. Culture system III was optimal for porcine TDSC proliferation in vitro. Lines on the top of the bars show comparison of the average generation time of different culture systems. ${ }^{* *} \mathrm{P}<0.05$, represents a negative hypothesis for the generation time for culture system I vs. II and III, respectively. While, the comparison between culture system I and II represents no significant differences. Data are expressed as the means \pm SD in triplicate.

P3, P6 and P10 in the first 2 days, and entered the logarithmic phase reaching the plateau phase at day 7 , the decline phase was about 8 days later. The PDT of porcine TDSCs was calculated to be $33.6 \pm 0.17 \mathrm{~h}$ for passage $3,35.1 \pm 0.21 \mathrm{~h}$ for passage 6 and $73.1 \pm 0.43 \mathrm{~h}$ for passage 10 .

Colony-forming cell assay of TDSCs. Clonogenicity is a property of stem cells. Cultured in complete medium, individual cell formed colonies after 8 days. Colonies were observed under a microscope after Giemsa staining (Fig. 4). In this study, the colony-forming rates were $36.97 \pm 0.07 \%$, $32.54 \pm 0.71 \%, 17.34 \pm 0.21 \%$ and $9.43 \pm 0.19 \%$ for passage 2,6 , 
A

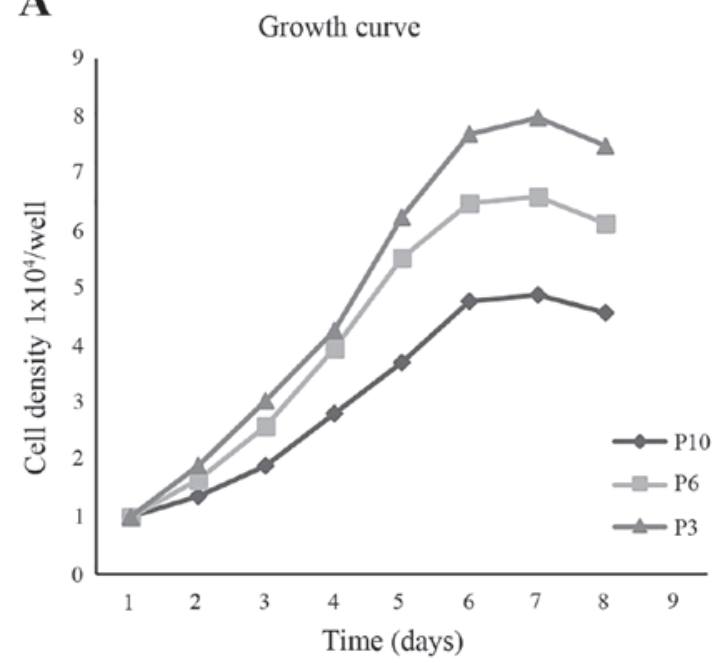

B

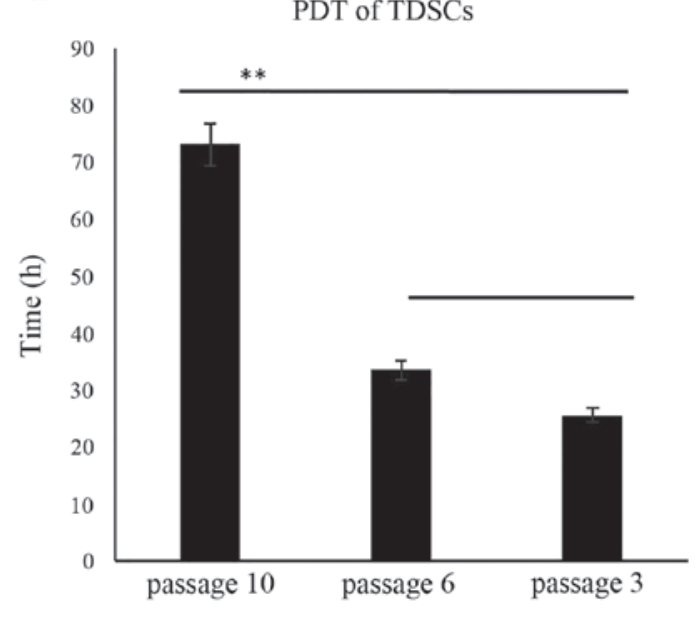

Figure 3. (A) The growth curves of pig TDSCs at P3, P6 and P10. Curves were all typically sigmoidal, including latent, logarithmic, plateau and decline phases. (B) The PDT was about $33.6 \pm 0.17 \mathrm{~h}, 35.1 \pm 0.21 \mathrm{~h}$ and $73.1 \pm 0.43 \mathrm{~h}$, respectively. The results are shown as the means \pm SD in triplicate. Lines on the top of the bars show comparisons of the PDT at different generations by t-test, among which, ${ }^{* *} \mathrm{P}<0.05$ represents significant difference for P10 vs. P6 and P3, respectively, while comparison between P3 and P6 showed no significant difference. TDSCs, tendon-derived stem cells; PDT, population doubling time.

A

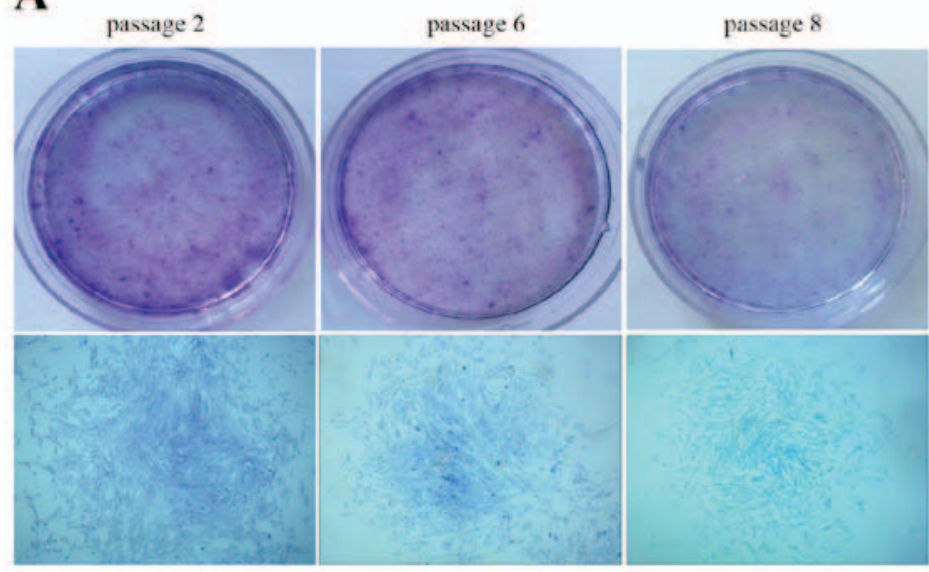

passage 10

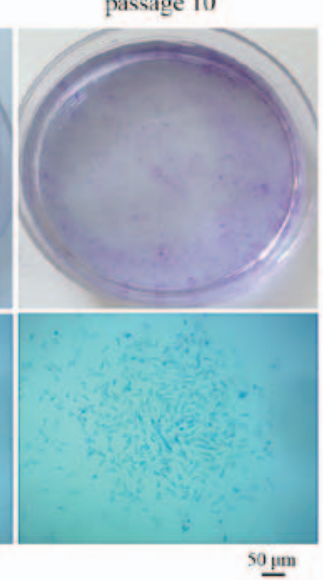

\section{B}

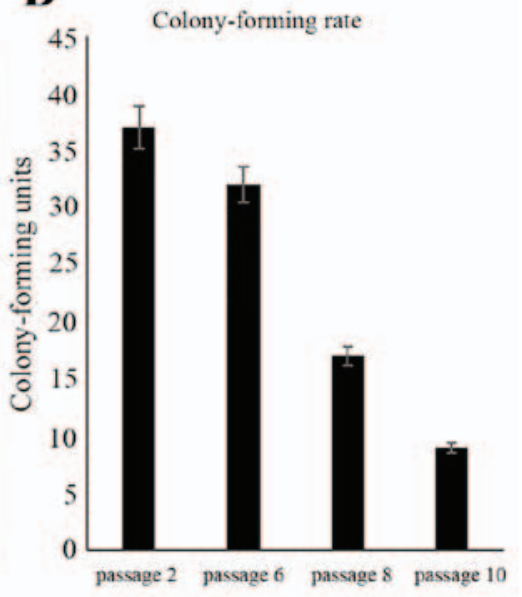

Figure 4. The clonogenicity and the colony-forming rate of porcine TDSCs. (A) Formation of colonies of porcine TDSCs at different passages after culturing for 8 days and stained with Giemsa. Formation of colonies was photographed at x40 magnification under an inverted microscope (scale bar, $50 \mu \mathrm{m}$ ). (B) Bar chart shows the colony-forming rate of different passages of porcine TDSCs. The results are shown as the means \pm SD in triplicate. TDSCs, tendon-derived stem cells.

8 and 10, respectively, which demonstrated the self-renewal ability of porcine TDSCs of different passages.

Karyotype analysis. The diploid chromosome number of porcine TDSCs was $2 \mathrm{n}=38$, consisting of 18 pairs of autosomes and one pair of sex chromosomes XX (o) or XY $\left(0^{7}\right)$. The morphology of chromosomes is shown in Fig. 5. The chromosome numbers were counted in 100 spreads from different passages to calculate the diploid rates in this study, which was about $96 \%$, indicating that TDSCs had genetic stability.

Identification of porcine TDSCs. The specific surface antigen markers of porcine TDSCs were detected via immunofluorescence (Fig. 6A) and RT-PCR (Fig. 6B), the immunofluorescence results showed that TDSCs expressed stem cell specific markers CD90 and tenocytes specific markers, such as collagen I, collagen III, CD105 and $\alpha$-SMA. RT-PCR assay indicated that porcine TDSCs at passage 3, 6 and 10 expressed tenocyte-specific genes, collagens I and III, but did not express collagen II.

Multipotent differentiation of TDSCs in vitro. In this study, the multi-lineage differentiation potential of porcine TDSCs was performed for osteogenic, chondrogenic and adipogenic induction medium. The negative control cells for every type of differentiation were cultured in complete culture medium. After incubating in induction medium for 2-4 weeks, the induced cells changed in shape and were positive for Alizarin Red S, Oil Red O and Alcian blue 8GX staining, respectively. Cells began to show obvious morphological changes after incubated in osteogenic medium for 2 weeks (Fig. 7Aa), cells formed mineralized nodules which were stained with 


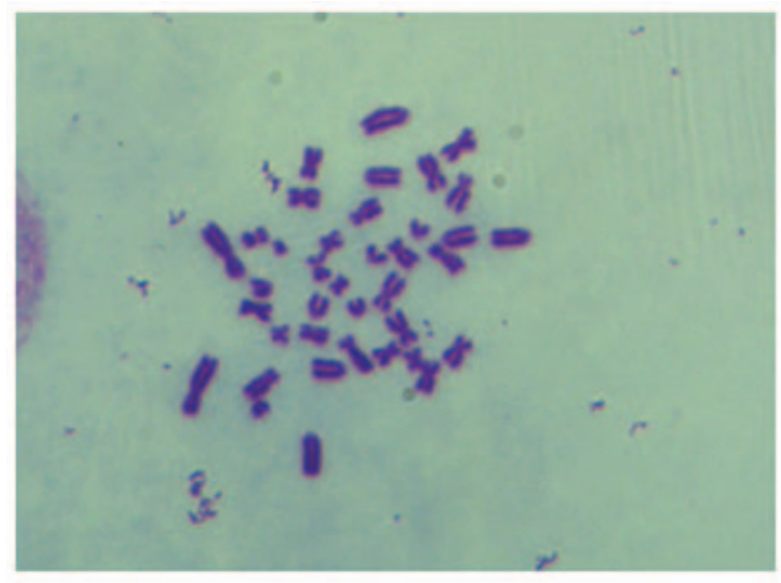

\begin{tabular}{|c|c|c|c|c|c|c|}
\hline 1 & 2 & 3 & 4 & 5 & 6 & \\
\hline 88 & $\mathbf{i n}$ & Ih & 88 & $x x$ & $\mathbf{x x}$ & \\
\hline 7 & 8 & 9 & 10 & 11 & 12 & \\
\hline $\mathbf{X x}$ & 21 & X & $x=$ & $x x$ & Xo & \\
\hline 13 & 14 & 15 & 16 & 17 & 18 & $x x$ \\
\hline 10 & BO & $\Delta \cap$ & mn & na & no & มถ \\
\hline
\end{tabular}

Figure 5. Chromosomes at metaphase and karyotype of porcine TDSCs. The chromosomes number of the pig was $2 \mathrm{n}=38$, which contains 18 pairs of autosomes and a pair of sex chromosomes. A representative XY ( $\left.\sigma^{\top}\right)$ type spread in metaphase is shown $(\mathrm{n}=100)$. TDSCs, tendon-derived stem cells.
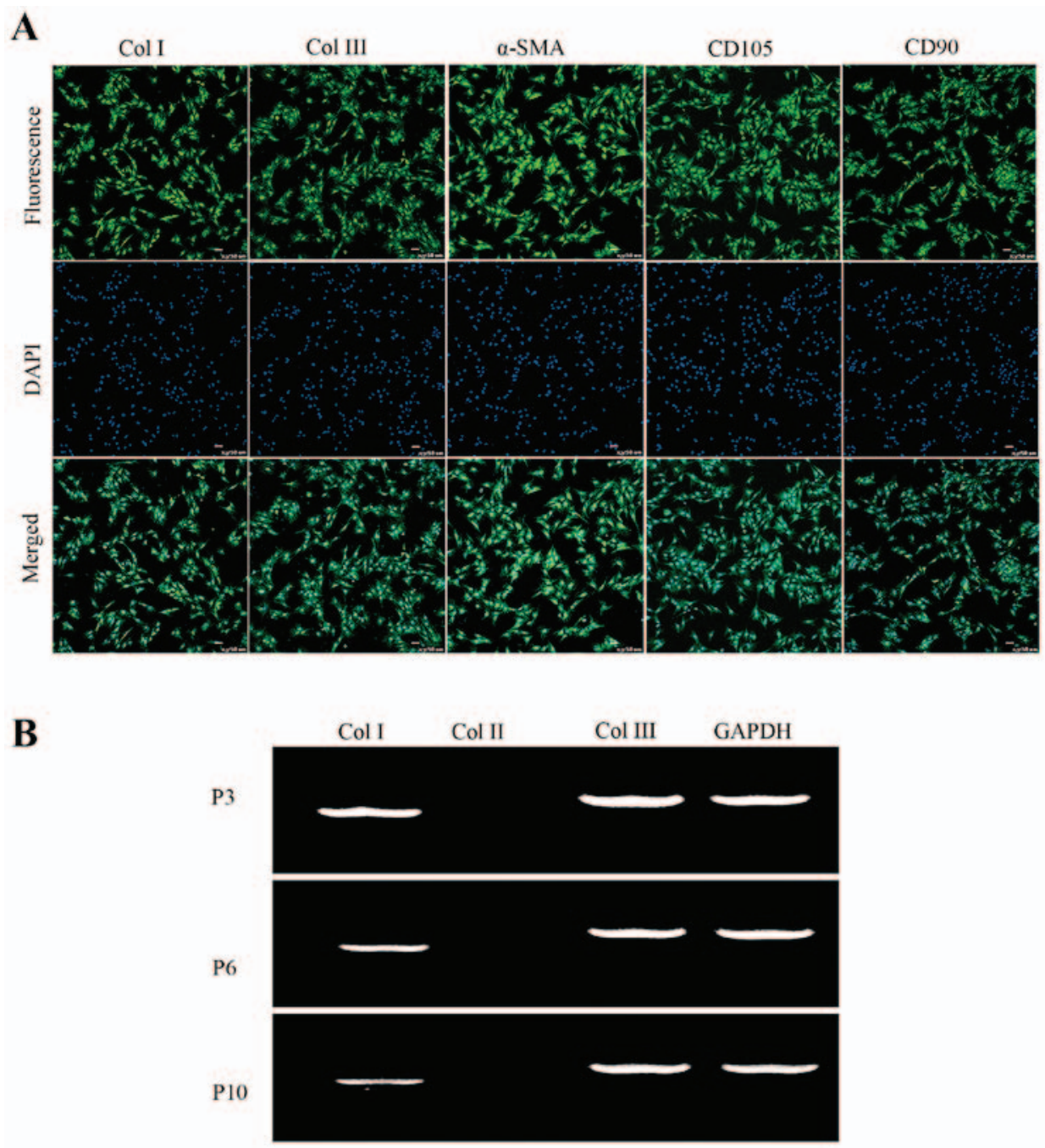

Figure 6. Identification of porcine TDSCs. (A) Characterization of surface markers of TDSCs by immunofluorescence staining. Specific surface markers of TDSCs were collagen I, collagen III, CD90, CD105 and $\alpha$-SMA were positively expressed (scale bar, $50 \mu \mathrm{m}$ ). (B) Detection of porcine TDSC-specific genes by RT-PCR. The results showed that the specific genes of TDSCs, collagen I and III, were positive, however, collagen II, the specific gene of chondrocytes, was negatively expressed. GAPDH served as internal control. TDSCs, tendon-derived stem cells; $\alpha$-SMA, $\alpha$-smooth muscle actin.

Alizarin Red S (Fig. 7Ab and c); while control group cells showed no obvious change in morphology and were positive for Alizarin Red S (Fig. 7Ad). Osteogenic differentiation of
TDSCs was also analyzed by RT-PCR. Osteogenic-specific genes ALP, RUNX2 and OPN were positively expressed in the induced group (Fig. 7Bb), but negative in control 
A
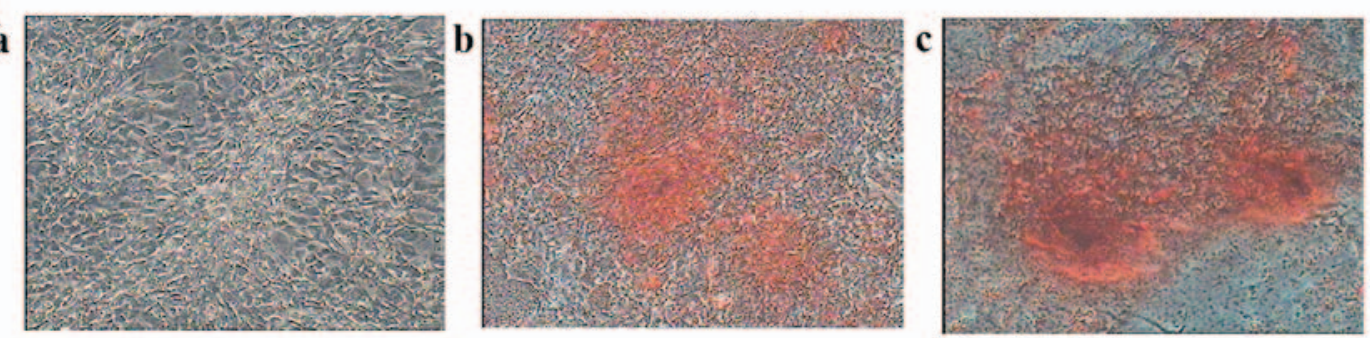

d

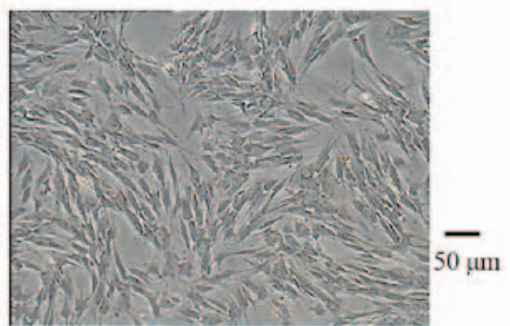

B

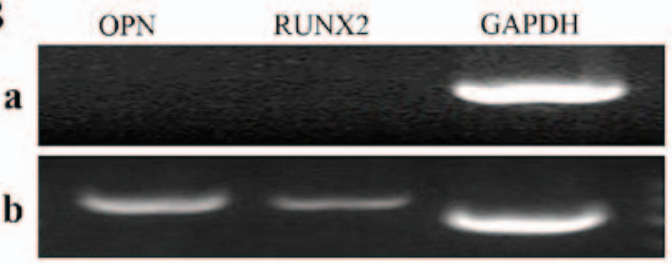

Figure 7. Osteogenic differentiation of porcine TDSCs. (A) The morphological change of cells in control and induction groups, (a) cells showed obvious changes in morphology and formed calcified deposition after induction for 14 days (magnification, $\mathrm{x} 40$ ), (b and c) extracellular calcium dispositions were positive for Alizarin Red S staining [(b) magnification, x40; (c) magnification, x100]. (d) The control group was negative for Alizarin Red S staining (magnification, x40). (B) RT-PCR showed that (b) the induced group expressed the osteoblast-specific genes OPN and Runx2, whereas (a) the control group did not express these genes. GAPDH served as the internal control (scale bar, $50 \mu \mathrm{m}$ ). TDSCs, tendon-derived stem cells.

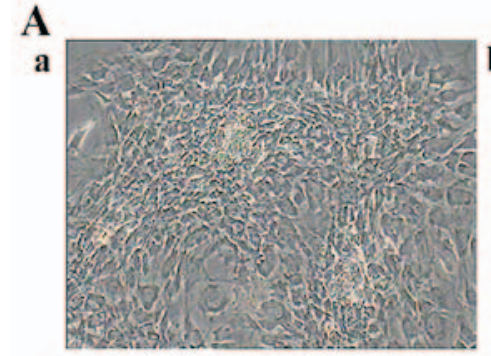

d

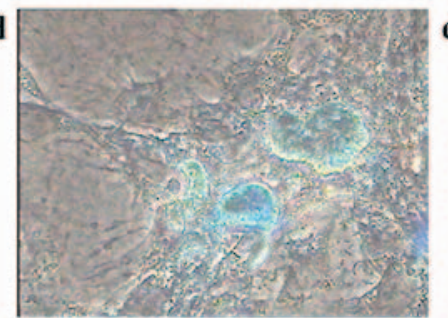

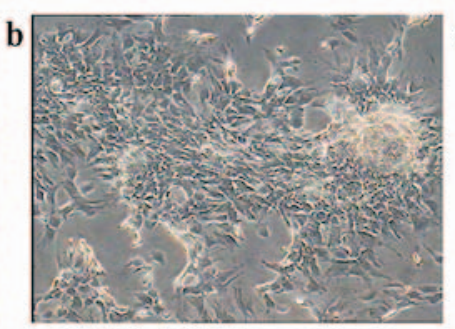

e

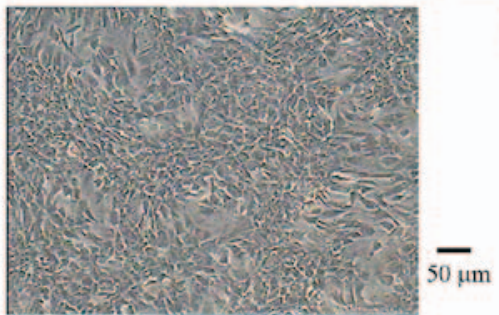

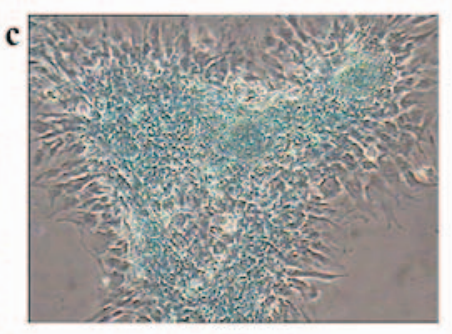

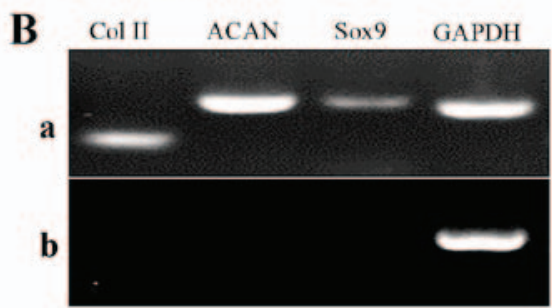

Figure 8. Chondrogenic differentiation of porcine TDSCs. (A) The morphological change of cells stained by Alcian blue 8GX staining. (a and b) The induced cells changed in shape and formed proteoglycans in extracellular matrix 21 days later (magnification, x40); (c and d) induced cells were positive for Alcian blue 8GX staining [(c) magnification, x100; (d) magnification, x200]. (e) Control cells showed no morphological change and were negative for Alcian blue 8GX staining (magnification, x40). (B) RT-PCR showed that (b) the induced cells expressed chondrogenic-specific genes collagen II, ACAN and Sox9, (a) the control group, however, did not express these genes. GAPDH served as the internal control (scale bar, $50 \mu \mathrm{m}$ ). TDSCs, tendon-derived stem cells.

group (Fig. 7Ba); cells induced in chondrogenic differentiation medium were densely packed with phase-bright cell clusters (Fig. 8Aa), during the third week, the flatter cells surrounding the 3D cell aggregates began to detach (Fig. 8Ab), leaving behind the $3 \mathrm{D}$ cell aggregates and stained with Alcian blue 8GX (Fig. 8Ac and d), control group cells were negative for Alcian blue 8GX (Fig. 8Ae). RT-PCR showed that chondrogenic-specific genes Sox9, ACAN were expressed in the induced group (Fig. 8Ba) but not in the control group (Fig. 8Bb); adipogenic differentiation of TDSCs was demonstrated by Oil Red $\mathrm{O}$ staining. After incubation in adipogenic medium for 2 weeks, porcine TDSCs changed in shape and many intracellular lipid droplets aggregated to form larger droplets (Fig. 9Aa and b), which were then stained by Oil Red O staining, lipid droplets in orange (Fig. 9Ac and d) and the control group cells did not show any colour (Fig. 9Ae). RT-PCR results showed that adipocyte-specific genes PPAR- $\gamma$ and LPL expressed in the inducted group (Fig. 9Bb) but not in control group (Fig. 9Ba).

\section{Discussion}

Tendinopathy and tendon rupture are most common disorders in competitive sports and in daily life (24), which impairs active performance in athletes and workers. The traditional treatment of tendon injuries have high recurrence rates. 


\section{A}
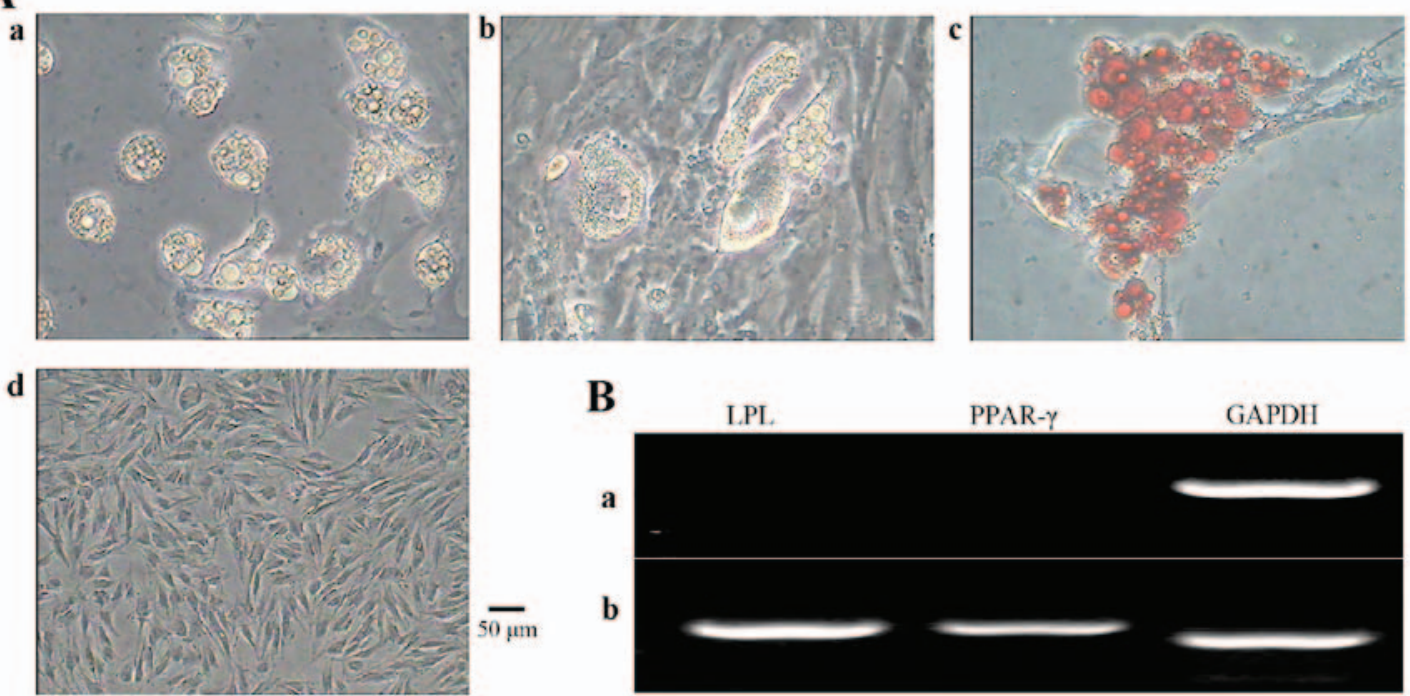

B

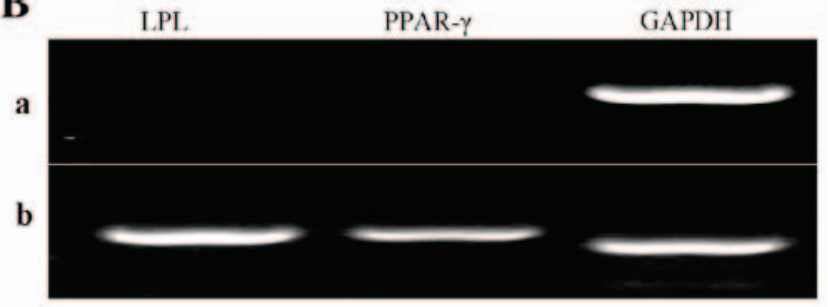

Figure 9. Adipogenic differentiation of TDSCs. (Aa) TDSCs began to form some intracellular neutral lipid droplet (magnification, x40) and (b) droplets increased and aggregated to form larger ones as induction progressed (magnification, x100). (c) Droplets were positive for Oil Red O dye (magnification, x100). (d) Control group cells showed no obviously change in shape and were negative for Oil Red O dye (magnification, x40). (B) RT-PCR showed that (b) induction group expressed adipocyte-specific genes PPAR- $\gamma$ and LPL, whereas (a) the control group did not. GAPDH served as the internal control. Scale bar, $50 \mu \mathrm{m}$. TDSCs, tendon-derived stem cells.

Currently, cell therapy is considered a valuable strategy for the treatment of untreatable diseases in veterinary medicine and sports medicine $(21,25)$, and there is an increasing interests in TDSCs. In this experiment, the TDSCs were successfully isolated from 1-day-old porcine tendon tissues and freshly isolated cells were subcultured up to passage 11 in vitro, these cells had strong clonogenicity, high proliferative potential and multi-differentiation potential which indicated that TDSCs possess stem cell characteristic, and were identified as TDSCs.

The cultured protocols of TDSCs in vitro were established in different species and the ingredients of complete culture medium may differ between species to some degree. Through a series of trials, the complete culture medium of porcine TDSCs in this study were optimized, which reduced average generation time, indicating that the culture system III, which added factors bFGF and SCF, in comparison with others, promoted the proliferation of TDSCs and retained cells regenerative capacity in vitro.

In this experiment, several surface markers have been used to characterize porcine TDSCs in vitro, such as collagen I, collagen III, $\alpha$-SMA, CD105 and CD90. The freshly isolated TDSCs highly expressed CD90 which is a stem cell marker and was used for characterization of human MSCs; CD105, a co-receptor of the TGF- $\beta$ super-family, which was also positively expressed in TDSCs. Some findings indicated that the TDSCs of mice contained two subpopulations, one positive and one negative for $\mathrm{CD} 105$, and the $\mathrm{CD} 105$-negative cells displayed obvious chondrogenic ability compared with the CD105-positive ones (12). In addition to the stem cell markers, we also studied the expression of lineage-specific markers, including collagen I, collagen III and $\alpha$-SMA, which were highly expressed in TDSCs of pig. We also tested the expression of specific genes, collagen I, II and III. The results showed that tenocyte-specific genes collagen I and II expressed positively while collagen II, the chondrocyte-specific gene, expressed negatively, which was consistent with previous studies.

In the current research, the mechanism of tendon injuries remains unknown, previous studies considered both mechanical and biological microenvironment as significant factors (26) that contribute to the altered fate of TDSCs. The multi-differentiation potential of porcine TDSCs toward adipogenesis, chondrogenesis and osteogenesis in vitro were tested in this investigation. By inducting TDSCs in three different induction media for 2-4 weeks, cells showed high differential capacity, which may contribute to pathological chondro-ossification and failed tendon healing when tendon were injured. The shortcoming of this experiment was that we failed to detect the expression of the corresponding protein and mRNA which may have a close relationship with the pathological mechanism of tendon injuries.

In conclusion, stem cells isolated from tendon tissue possessed common stem cell characteristics, such as self-renewal ability, clonogenicity, proliferation and multi-differentiation potential, which were demonstrated in this study. Porcine TDSCs not only expressed MSC markers but also expressed tenocyte-specific surface markers. Given their stem cell characteristics, we studied the isolation, identification and biological characteristics of porcine TDSCs in vitro. This investigation offered new opportunities of studying the biological characteristic of TDSCs, providing a platform for the exploration of pathological mechanism of tendon injuries, on this basis, the study of porcine TDSCs may offer a new source of stem cells for human regenerative medical therapies in animal models.

\section{Acknowledgements}

We thank Dr W. Guan, Professor Y. Liu and Dr Q. Zhao for assistance in preparing this manuscript. 


\section{Funding}

This research was supported by China Postdoctoral Science Foundation funded project (CPSFFP) (2015M571182), the Agricultural Science and Technology Innovation Program (ASTIP) (cxgc-ias-01) and the project National Infrastructure of Animal Germplasm Resources (2014).

\section{Availability of data and material}

The datasets used and/or analyzed during the current study are available from the corresponding author on reasonable request.

\section{Authors' contributions}

JY contributed to the concept and design, data analysis and interpretation and writing of the experimental section including cell culture, identification and induction. QZ contributed to the collection and assembly of data. KW contributed to the accomplishment of isolation of TDSCs and Primer design. CM and HL contributed to the accomplishment of RT-PCR assay. YL contributed to the concept and design of the study. WG contributed to the concept and design of the study, gave the final approval for the manuscript and arranged the financial support. All authors read and approved the final manuscript.

\section{Ethics approval and consent to participate}

The experimental protocols were approved by the Institutional Animal Care and Use Committee of the Chinese Academy of Agriculture of Sciences [permit no. SCXK (jing) 2015-0006].

\section{Consent for publication}

Not applicable.

\section{Competing interests}

The authors declare that they have no competing interests.

\section{References}

1. Vleck VE and Garbutt G: Injury and training characteristics of male elite, development squad, and club triathletes. Int J Sports Med 19: 38-42, 1998.

2. Allison GT and Purdam C: Eccentric loading for Achilles tendinopathy - strengthening or stretching? Br J Sports Med 43 276-279, 2009.

3. Mendias CL, Gumucio JP, Bakhurin KI, Lynch EB and Brooks SV: Physiological loading of tendons induces scleraxis expression in epitenon fibroblasts. J Orthop Res 30: 606-612, 2012.

4. Oliva F, Via AG and Maffulli N: Physiopathology of intratendinous calcific deposition. BMC Med 10: 95, 2012.

5. Young M: Stem cell applications in tendon disorders: A clinical perspective. Stem Cells Int 2012: 637836, 2012.

6. Hirzinger C, Tauber M, Korntner S, Quirchmayr M, Bauer HC, Traweger A and Tempfer H: ACL injuries and stem cell therapy. Arch Orthop Trauma Surg 134: 1573-1578, 2014.

7. Machova Urdzikova L, Sedlacek R, Suchy T, Amemori T, Ruzicka J, Lesny P, Havlas V, Sykova E and Jendelova P: Human multipotent mesenchymal stem cells improve healing after collagenase tendon injury in the rat. Biomed Eng Online 13: 42, 2014
8. Valencia Mora M, Ruiz Ibán MA,Díaz Heredia J,Barco Laakso R, Cuéllar R and García Arranz M: Stem cell therapy in the management of shoulder rotator cuff disorders. World J Stem Cells 7: 691-699, 2015.

9. Rui YF, Lui PPY, Li G, Fu SC, Lee YW and Chan KM: Isolation and characterization of multipotent rat tendon-derived stem cells. Tissue Eng Part A 16: 1549-1558, 2010.

10. Bi Y, Ehirchiou D, Kilts TM, Inkson CA, Embree MC, Sonoyama W, Li L, Leet AI, Seo BM, Zhang L, et al: Identification of tendon stem/progenitor cells and the role of the extracellular matrix in their niche. Nat Med 13: 1219-1227, 2007.

11. Lovati AB, Corradetti B, Lange Consiglio A, Recordati C, Bonacina E, Bizzaro D and Cremonesi F: Characterization and differentiation of equine tendon-derived progenitor cells. J Biol Regul Homeost Agents 25 (Suppl): S75-S84, 2011.

12. Asai S, Otsuru S, Candela ME, Cantley L, Uchibe K, Hofmann TJ, Zhang K, Wapner KL, Soslowsky LJ, Horwitz EM, et al: Tendon progenitor cells in injured tendons have strong chondrogenic potential: The CD105-negative subpopulation induces chondrogenic degeneration. Stem Cells 32: 3266-3277, 2014.

13. Gong X, Hou L, Bai C, Jin D, He X, Guan W and Ma Y: Isolation and biological characteristics of chicken adipose-derived progenitor cells. DNA Cell Biol 30: 453-460, 2011.

14. Sun CC, Su Pang JH, Cheng CY, Cheng HF, Lee YS, Ku WC, Hsiao $\mathrm{CH}$, Chen JK and Yang CM: Interleukin-1 receptor antagonist (IL-1RA) prevents apoptosis in ex vivo expansion of human limbal epithelial cells cultivated on human amniotic membrane. Stem Cells 24: 2130-2139, 2006.

15. Zhang JY and Wang JHC: Characterization of differential properties of rabbit tendon stem cells and tenocytes. BMC Musculoskel Dis 11: 10,2010.

16. Mensing N, Gasse H, Hambruch N, Haeger JD, Pfarrer C and Staszyk C: Isolation and characterization of multipotent mesenchymal stromal cells from the gingiva and the periodontal ligament of the horse. BMC Vet Res 7: 42, 2011.

17. Liu J, Chen L, Tao X and Tang K: Phosphoinositide 3-kinase/Akt signaling is essential for prostaglandin E2-induced osteogenic differentiation of rat tendon stem cells. Biochem Biophys Res Commun 435: 514-519, 2013.

18. Lui PPY, Fu SC, Chan LS, Hung LK and Chan KM: Chondrocyte phenotype and ectopic ossification in collagenase-induced tendon degeneration. J Histochem Cytochem 57: 91-100, 2009.

19. Tsai WC, Hsu CC, Chou SW, Chung CY, Chen J and Pang JHS: Effects of celecoxib on migration, proliferation and collagen expression of tendon cells. Connect Tissue Res 48: 46-51, 2007.

20. Bai C, Li X, Hou L, Zhang M, Guan W and Ma Y: Biological characterization of chicken mesenchymal stem/progenitor cells from umbilical cord Wharton's jelly. Mol Cell Biochem 376: 95-102, 2013

21. Tan Q, Lui PPY and Lee YW: In vivo identity of tendon stem cells and the roles of stem cells in tendon healing. Stem Cell Dev 22: 3128-3140, 2013.

22. Jiang K, Wang Z, Du Q, Yu J, Wang A and Xiong Y: A new TGF- $\beta 3$ controlled-released chitosan scaffold for tissue engineering synovial sheath. J Biomed Mater Res A 102: 801-807, 2014.

23. Mukherjee A and Rotwein P: Insulin-like growth factor-binding protein-5 inhibits osteoblast differentiation and skeletal growth by blocking insulin-like growth factor actions. Mol Endocrinol 22: 1238-1250, 2008

24. Clayton RAE and Court-Brown CM: The epidemiology of musculoskeletal tendinous and ligamentous injuries. Injury 39: 1338-1344, 2008

25. Watts AE, Yeager AE, Kopyov OV and Nixon AJ: Fetal derived embryonic-like stem cells improve healing in a large animal flexor tendonitis model. Stem Cell Res Ther 2: 4, 2011.

26. Kohler J, Popov C, Klotz B, Alberton P, Prall WC, Haasters F, Müller-Deubert S, Ebert R, Klein-Hitpass L, Jakob F, et al: Uncovering the cellular and molecular changes in tendon stem/progenitor cells attributed to tendon aging and degeneration. Aging Cell 12: 988-999, 2013. 